\title{
PENGARUHEDUKASI HIPERTENSI DENGAN MEDIA BOOKLET TERHADAP PERILAKU SELF MANAGEMENT PADA PASIEN HIPERTENSI DI WILAYAH PUSKESMAS BALOWERTI KEDIRI
}

\author{
Sri Wahyuni, M.Kep.,Ns \\ Dosen Prodi S1 Keperawatan, Fakultas Ilmu Kesehatan \\ IIK Bhakti Wiyata Kediri
}

\begin{abstract}
Background :Hypertension is a disease which can damage the organ progressively and settled, disease caused diseases such as stroke, cardiovascular disorders, kidney failure, and other serious diseases that threaten a person's life. Self management can be applied to patients with hypertension in an effort to enhancing the knowledge, attitudes and behavior.Objective :This research aims to the influence of education booklets media to self management in patients hypertension in the Puskesmas Balowerti Kota Kediri. Methods :This type of research is quantitative, with pre-post test design in one group (onegroup pre-post test design). The sample in this study were 30 respondents selected by accidental sampling.Results: based on the obtained paired T test p-value is $0.000<\alpha=$ 0.05 . Conclusions and recommendations :There is a significant effect of hypertension with the media giving education booklet on self management behaviors in patients with hypertension in the PuskesmasBalowerti Kediri. To improve the behavior of selfmanagement in hypertensive patients can consider the provision of structured edukas use media interest, so that more effective education.
\end{abstract}

\section{PENDAHULUAN}

Hipertensi menjadi salah satu penyakit"Silent Killer"dimana penyakit ini dapat merusak organ secara progresif dan menetap, akibat yang ditimbulkan penyakit hipertensi seperti stroke, gangguan kardiovaskular, gagal ginjal, dan penyakit berat lainnya yang dapat menyebabkan terancamnya kehidupan seseorang (Erkoc, 2012). Prevelensi hipertensi akan terus menerus mengalami peningkatan sehingga hal ini dapat menyebabkan permasalahan yang besar di dunia (Firmawati, 2011).

World Health Organization (WHO),padatahun 2008 sekitar 40\% orang dewasa yang telah mencapai usia 25 tahun keatas didiagnosis hipertensi diseluruh dunia, diperkirakan jumlah tersebut meningkat $60 \%$ atau sekitar 1,56 miliar tahun 2015 (WHO, 2013).Berdasarkan hasil Riset Kesehatan Dasar (2013) prevelensi hipertensi di Indonesia yang diperoleh dari questioner yang didiagnosis oleh tenaga kesehatan atau sedang minum obat sebesar $26,5 \%$
(Kemenkes RI, 2014).Berdasarkan hasil riset kesehatan dasar (2013) prevelensi hipertensi berdasarkan propinsi di Indonesia, Jawa Timur berada pada urutan ke 6 (Kemenkes RI, 2014). Di Kota Kediri pada tahun 2015, jumlah pasien hipertensi mencapai 25.640 dengan prevalensi di Puskesmas Balowerti sebanyak 3.752 pasien hipertensi (Dinkes Kediri, 2015).

Pasien hipertensi yang melakukan control tekanan darah dengan cara memodifikasi gaya hidup sekitar 30\% dari keseluruhan pasien hipertensi (Ragotet al, 2005).Self management dengan memonitoring tekanan darah, pengaturan makan, latihanfisik, pengontrolan berat badan, pengelolaan stress, berhenti merokok, menghindari alcohol dan penggunaan obat dapat dijadikan sebagai salah satu upaya untuk mencegah komplikasi hipertensi. Hasil penelitian Hayes (2010), pengelolaan hipertensi efektif dengan cara berhenti merokok, pengaturan pola makan sehat dan melakukan latihan fisik secara teratur.Perubahan perilaku dapat 
dimanfaatkan sebagai cara mengurangi atau menghambat akibat yang tidak diinginkan pada pasien hipertensi (Hayes, 2010).

Self management dapat diaplikasikan pada pasien hipertensi untuk peningkatkan pengetahuan, sikap dan perilaku dengan menggunakan metode pembelajaran ceramah dengan media booklet (Lee, 2013). Kelebihan media booklet yaitu dapat dilihat dari segi biaya yang dikeluarkan cukup murah karena hanya dengan menggunakan media cetak, pesan yang disampaikan pada media booklet dapat disesuaikan dengan keadaan saat ini karena dapat memuat topik secara detail dan jelas serta bisa lebih mengembangkan pesan yang akan disampaikan (Yulianti, 2013).

Berdasarkan hasilkajian di atas, menjadi penting untuk dilakukan penelitian lebih lanjut terkait "Pengaruh Edukasi Hipertensi dengan Media Booklet terhadap Perilaku Self Management pada Pasien Hipertensi di Wilayah Puskesmas Balowerti Kota Kediri”.

\section{METODE PENELITIAN}

Pada penelitian ini menggunakan desain penelitian praeksperimental dengan rancangan pre-pesca test dengan satu kelompok (one-group pra-post test design). Kelompok subjek diobservasi sebelum dilakukan intervensi, kemudian dievaluasi setelah diberikan intervensi. Kriteria inklusi pada penelitian ini yaitu pasiendengan hipertensi stadium 1 (TDS : 140-159 mmHg, TDD : 90-99 $\mathrm{mmHg}$ ) dan stadium 2 (TDS : >160 mmHg, TDD : $>100 \mathrm{mmHg}$ ), mampu melakukan aktifitas fisik dengan baik, memiliki kemampuan membaca yang baik, pasien tidak memiliki keterbatasan fisik.Teknik sampling pada penelitian ini menggunakan accidental sampling. Jumlah pasien yang memenuhi kriteria adalah 30 orang.

Langkah pertama menentukan pasien, langkah kedua mempersiapkan kuesioner dan Booklet, kemudian langkah ketiga yaitu menjelaskan kepada pasien tentang penelitian yang akan dilakukan dengan cara mengobservasi perilaku self management hipertensi, langkah kelima yaitu melihat sejauh mana pasien mengetahui tentang perilaku self management hipertensi pasien dengan menggunakan kuesioner, selanjutnya langkah keenam yaitu di berikan intervensi edukasi hipertensi dengan media Booklet. Langkah terakhir yaitu mengevaluasi kembali perilaku self management hipertensi pasien dengan menggunakan kuesioner.

\section{HASIL PENELITIAN}

1.Rata-rata perilaku self management pasien sebelum dan sesudah diberikan intervensi edukasi hipertensi.

Tabel 1Hasil rata-rata perilaku self management sebelum dan sesudah diberikan edukasi hipertensi di Puskesmas Balowerti Kediri Tahun 2016.

\begin{tabular}{llcccccc}
\hline $\begin{array}{c}\mathrm{N} \\
\mathrm{o}\end{array}$ & $\begin{array}{c}\text { Vari } \\
\text { an }\end{array}$ & $\mathrm{N}$ & $\begin{array}{c}\text { Mea } \\
\mathrm{n}\end{array}$ & $\begin{array}{c}\mathrm{Mi} \\
\mathrm{n} .\end{array}$ & $\begin{array}{c}\mathrm{M} \\
\text { ax. }\end{array}$ & SD & $p$ \\
\hline 1 & Sebe & 3 & 56,5 & 50, & 66, & 4,80 & 0,11 \\
& lum & 0 & 333 & 00 & 00 & 469 & 9 \\
\hline 2 & Sesu & 3 & 77,2 & 70, & 82, & 3,01 & 0,81 \\
& dah & 0 & 333 & 00 & 00 & 357 & 5 \\
\hline
\end{tabular}

didapatkan mean perilaku self management pasien sebelum diberikan intervensi edukasi hipertensi adalah 56,5333 dengan Standar Deviasi 4,80469. Pada tabel test of normality shapiro-Wilk didapatkan p-value 0,119. Sedangkan mean perilaku self management pasien sesudah diberikan intervensi edukasi hipertensi adalah 77,2333dengan standar Deviasi 3,01357. Pada tabel test of normality shapiro-Wilk didapatkan $\mathrm{p}$ value 0,815 . Dapat di artikan nilai $p$-value lebih besar dari nilai $\alpha(0,05)$ maka dapat disimpulkan distribusi data perilaku pasien sebelum dan sesudah di berikan 
intervensi edukasi hipertensi adalahberdistribusi normal.

\section{Hasil Uji Paired t test}

Tabel 2Hasil uji test $t$ paired edukasi hipertensi dengan media booklet terhadap perilaku self management pada pasien hipertensi di Puskesmas Balowerti Kediri Tahun 2016

\begin{tabular}{lcccccc}
\hline $\begin{array}{l}\text { Var } \\
\text { ian }\end{array}$ & $\mathrm{N}$ & Mean & Min. & $\begin{array}{c}\text { Ma } \\
\text { x. }\end{array}$ & $\begin{array}{c}\mathrm{S} \\
\mathrm{D}\end{array}$ & $\begin{array}{c}p- \\
\text { value }\end{array}$ \\
\hline Rat & 3 & - & - & - & 5, & 0,000 \\
a- & 0 & 20,700 & 22,7 & 18, & 49 & \\
rata & 00 & 5028 & 649 & 07 & \\
& & & & 72 & 4 & \\
\hline
\end{tabular}

Data dari tabel 2 di atas didapatkan hasil uji Paired $t$ testdidapatkan nilai $p$-value adalah $0,000<\alpha=0,05$ artinya terdapat pengaruh yang signifikan pemberian edukasi hipertensi dengan media booklet terhadap perilaku self management pada pasien hipertensi di Puskesmas Balowerti Kediri.

\section{PEMBAHASAN}

\section{A. Pembahasan}

1. Perilaku self management sebelum dan sesudah diberikan edukasi hipertensi

Hasil rata-rata perilaku self management sebelum diberikan intervensi edukasi pada tabel 1 yaitu 56,53. Hasil rata-rata perilaku self management sesudah diberikan intervensi edukasi pada tabel 1 yaitu 77,23.

Edukasi kesehatan merupakan pengembangan serta penyediaan perintah melalui kebiasaan pembelajaran yang terkontrol sehingga diperoleh perilaku kondusif untuk selalu hidup sehat pada individu, keluarga, kelompok dan komunitas (Dotcherman \& Bulechek, 2008).Edukasi juga merupakan pembelajaran yang didasari oleh proses interaktif dan juga upaya dalam menambah pengetahuan baru, sikap, ketrampilan melalui pembelajaran praktik dan pengalaman (Smeltzer\& Bare, 2008). Menurut Edelman dan Mandle (2002) dalam Widiastuti (2012) tujuan dilakukannya edukasi kesehatan yaitu supaya seseorang bias memperoleh kesehatan yang optimal melalui usahanya sendiri.

Pasien hipertensi di Puskesmas Balowerti masih beranggapan jika gejala hipertensi timbul cukup hanya diberikan obat saja untuk menghilangkannya dan tidak tahu bagaimana cara mencegah gejala hipertensi tersebut terjadi. Peran perawat di sini membantu pasien hipertensi untuk memahami bagaimana cara memanajemen diri agar tidak terjadi gejala atau komplikasi dari hipertensi, diperlukan pengetahuan dan kepercayaan diri yang kuat dari pasien hipertensi dalam menjalani terapi atau perawatan hipertensinya.

Dari tabel 1 didapatkan peningkatan mean sebelum dansesudah diberikan intervensi edukasi hipertensi dari 56,53 77,23 , ada selisih antara nilaisebesar 20.7. dengan demikian dapat disimpulkan terjadi peningkatan perilaku self management pada pasien hipertensi setelah diberikan edukasi hipertensi dengan media booklet.

Pemberian edukasi hipertensi dengan media bookletpada pasien hipertensi di Puskesmas Balowerti dilakukan secara personal yaitu peneliti mendatangi rumah pasien satu persatu dan memberikan edukasi di rumah pasien. Para pasien sangat antusias dalam pemberian edukasi tersebut, adabeberapa pasienyang baru mengetahui cara perawatan hipertensi yang baik setelah diberikan edukasi. Sebagian besar pengetahuan pasien tentang hipertensi hanya sebatas obat dan menghindari makanan yang mengandung garam. Utuk pengelolaan hipertensi lain seperti olahraga, mengelola stress dan pola hidup yang sehat jarang dilakukan. Pasien dapat menerima edukasi dari peneliti dengan baik walaupun ada beberapa pasien belum memahami apa yg dijelaskan peneliti dan minta diulang penjelasan materi edukasinya.

Dari pelaksanaan penelitian di Puskesmas Balowerti ini peneliti 
mengamati kelebihan dari metode edukasi yang dilakukan yaitupasien mudah membaca setiap saat jika lupa. Pasien hipertensi di Puskesmas Balowerti menganggap booklet yang dibuat oleh peneliti sebagaibuku panduan sebagai acuan untuk mengontrol hipertensinya.

\section{Menganalisis Perilaku Self} Management Sebelum dan Sesudah Edukasi Hipertensi dengan media booklet

Berdasarkan hasil analisis pada tabel 2 dengan menggunakan uji $T$ Paired didapatkan nilai $p$-value adalah $0,000<\alpha=0,05$ artinya terdapat pengaruh yang signifikan pemberian edukasi hipertensi dengan media booklet terhadap perilaku self management pada pasien hipertensi di Puskesmas Balowerti Kota Kediri.

Pemberian edukasi hipertensi pada penelitian ini menggunakan media booklet yaitu suatu alat atau media untuk memberikan atau penyampaian pesan berbentuk buku yang berisi tulisan atupun gambar (Suiraoka, et al, 2012). Program edukasi diberikan dalam rangka peningkatkan pengetahuan pasien tentang penyakitnya dan supaya pasien dapat meningkatkan kemampuandalam melakukan aktifitas perawatanpada diri sendiri (Parsellet al, 2004).

Self management mendorong pasien menggunakan sumber daya yang ada untuk mengatasi gejala yang dialami terutama pada pasien penyakit kronis,self management memfasilitasi pasien untuk aktivitas pencegahan dan pengobatan dan diperlukan kerjasama dengan tenaga kesehatan lain, dengan pendidikan kesehatan akan mendorong kemandirian pasien sehingga mengelola penyakit secara mandiri (Warsiet al, 2004). Peningkatan pengetahuan yang diperole hpada pasien hipertensi di wilayah Puskesmas Balowerti diperoleh hasil significan, keyakinan diri pasien meningkat terhadap pengelolaan hipertensi dukungan dari keluarga dan orang-orang terdekat dapat mempengaruhi peningkatan perilaku self management pasien hipertensi. Petugas kesehatan juga sebagai fasilitator dan pengawas dalam terapi pengobatan pada pasien hipertensi juga sangat ikut mengambil peran.

Dari pernyataan diatas dapat disimpulkan bahwa salah satu upaya peningkatan perilaku self management pada pasien hipertensi yaitu dengan pemberian edukasi secara yang menarik yaitu dengan menggunakan media booklet. Sehingga diharapkan pasien hipertensi dapat melakukan perawatan di rumah dan mematuhi terapi yang akan berdampak pada penekanan angka kematian dan komplikasi penyakit hipertensi.

\section{PENUTUP}

\section{A. Kesimpulan}

1. Perilaku self management pasien sebelum diberikan edukasi hipertensi diperoleh hasil mean $56,53$.

2. Perilaku self managementpasien sesudah diberikan edukasi hipertensi diperoleh hasil Mean 77,23.

3. Dari analisis perilaku self management sebelum dan sesudah diberikan edukasi hipertensi dengan hasil uji T Paired didapatkan nilai $p$ value adalah $0,000<\alpha=0,05$ artinya terdapat pengaruh yang signifikan menggunakan edukasi hipertensi dengan media booklet terhadap perilaku self management pada pasien hipertensi.

\section{B. Saran}

1. Bagi petugas kesehatan

a. Diharapkan petugas puskesmas untuk berupaya melakukan komunikasi atau edukasi yang efektif agar pasien memahami sepenuhnya tentang penyakit yang diderita.

b. Petugas puskesmas dapat meningkatkan perilaku self management pada pasien 
hipertensiyang adaptif melalui pendidikan kesehatan yang terstruktur menggunakan berbagai media agar menarik, sehingga edukasi lebih efektif.

c. Petugas puskesmas dapat menjadi fasilitator untuk menghubungkan pasien hipertensi dengan sumber-sumber dukungan sosial baik keluarga, tenaga kesehatan maupun kelompok pendukung yang berguna untuk mempertahankan kondisi emosional pasien ke arah yang adaptif.

2. Bagi peneliti selanjutnya

a. Saat melakukan penelitian diusahakan bahasa yang disampaikan bisa di pahami oleh pasien hipertensi dalam upaya meningkatkan perilaku self management nya.

b. Lebih mengoptimalkan edukasi dan komunikasi agar tidak terjadi kesalahan dalam pemberian materi edukasi (melihat perilaku self managementnya).

c. Saat melakukan penelitian diusahakan untuk memberikan edukasi tidak hanya sekali, tetapi dilakukan selama beberapa pertemuan. Bagi peneliti selanjutnya dapat merubah variabel sebelumnya yaitu injeksi insulin pen dengan obat oral DM.

\section{DAFTAR PUSTAKA}

Dinkes Kediri. 2015. Jumlah Penderita Hipertensi Tahun 2014 dan 2015 Di Kota Kediri.

Dotchterman, J. \&Bulechek. 2008. Clinical Aplication of Nursing; Adult, Childs, Womans, Nursing Intervention. Classification Nursing Intervention,
Classification The International Journal of Nursing.

Erkoc S. B., Iskli, B, Metintas, S., Kalyoncu, C. 2012. Hypertension knowledge-level scale (HK-LS): a study on Development, validity and reliability. Int. J. Environ Res Puublic Health. 2012 Mar; 9 (3): 1018-1029.

Firmawati, dkk. 2011. Pengaruh Blog Edukatif Tentang Hipertensi Terhadap Pengetahuan Tentang Hipertensi dan Perilaku Diet Hipertensi pada Pasien Hipertensi di Wilayah Kerja Puskesmas Wirobrajan Yogyakarta. Muhammadiyah Journal of Nursing Vol 1, No 2 (2014).

Hayes, M. K. 2010. Influence of Age and Health Behaviors on Stroke Risk: Lession Form Longitudinal Studies. National Institute of Health. October 2010. 58 (suppl 2): S325-S328.

KementrianKesehatanRepublik Indonesia. 2014. Profil Kesehatan Indonesia 2013.

Lee, J.K. 2013. Evaluation of $a$ Medication Self Management Education Program for Elderly with Hypertension Living in the Community. J. Korean Acad Nurs. 43 (2): 267-275.

Persell, D.S., Keating, L., Nancy., \& Landrum. 2004. Relatiohship of diabetes speciffic knowladge to self managment activities, ambulatory preventive care and metabolic outcomes. Preventive Medicine, 39 (4), 746-752.

Ragot S., Sosner P., Bouche G., Guillemain J., \& Herpin D. 2005. Appraisal of the Knowledge of Hypertensive Patients and Assesments of the Role of the Pharmacists in the Management of Hypertension: Results of a Regional Survey. Journal of Human Hypertension, 19, 577-584 
Richard, A. A., \& Sea, K., 2011. Delineation of Self-Care and Associated Concepts. J Nurs Scholarsh. 43(3). 255-264.

Smeltzer,S.C. \& Bare, G. 2008. Brunner \&Suddarth's Textbook of medical Surgical Nursing. Philadelpia: Lippincott.

Suiraoka, LP., \& Supriasa, LD. 2012. Media Pendidikan Kesehatan. Yogyakarta: Graha Ilmu.

Warsi et al. 2004.A Systematic Review and Methodological Critique of the Literature.Original Investigation Self-Management Education Programs in Chronic Disease. Arch. Intern. Med/Vol.164,Aug 9/23, 2004.

Widiastuti. 2012.Efektififtas Edukasi terstruktur Berbasis Teori Perilaku Terencana Terhadap Pemberdayaan dan Kualitas Hidup Pasien Penyakit Jantung Koroner Di Rumah Sakit Pondok Indah Jakarta. Tesis. Universitas Indonesia.

World Health Organization (WHO). 2013. A global brief on hypertension: silent killer, global public health crisis. World Health Organization

Yulianti, Indah. 2013. Booklet untuk meningkatkan pengetahuan pemberantasan sarang nyamuk (PSN) Demam Berdarah Dengue (DBD) di Desa Plumbungan Kecamatan Karang Malang Kabupaten Sragen. Unnes Journal of Public Health, 2 (2) 2013. 